\title{
The Role of Mitochondrial Energy Metabolism in Shaping the Quality of Highbush Blueberry Fruit During Storage in Ozone-Enriched Atmosphere
}

\author{
Tomasz Piechowiak $^{1}$ [D $\cdot$ Patrycja Sowa $^{2} \cdot$ Maria Tarapatskyy $^{2} \cdot$ Maciej Balawejder $^{1}$
}

Received: 14 June 2021 / Accepted: 17 August 2021 / Published online: 2 September 2021

(c) The Author(s) 2021

\begin{abstract}
The aim of this study was to evaluate the effect of ozone treatment on the mitochondrial energy metabolism in blueberry fruit during storage as well as to determine the relationship between the activity of mitochondria and the antioxidative properties of ozonated fruit. Blueberry fruit was stored for 28 days at $4{ }^{\circ} \mathrm{C}$ and ozonated daily with gaseous ozone at the concentration of $15 \mathrm{mg} \mathrm{L}^{-1}$ for $30 \mathrm{~min}$, every $12 \mathrm{~h}$ of storage. Research showed that ozonated fruit was characterized by higher activity of enzymes involved in oxidative phosphorylation (by $58.7 \%$ for $\mathrm{SDH}, 118.2 \%$ for $\mathrm{CCO}$, and $78.16 \%$ for $\mathrm{H}^{+}$-ATPase after 7 days, respectively) than non-ozonated sample, which contributed to reduction of the loss of energy charge and ATP in the fruit during storage. Moreover, the increased activity of mitochondria led to the growth of mitochondrial ROS accumulation which, in turn, activated defense mechanisms against oxidative stress in the fruit. These metabolic responses might collectively contribute to increase the antioxidative properties of ozonated fruit and consequently to maintain a good quality of the fruit over a long period of storage.
\end{abstract}

Keywords Antioxidants $\cdot$ ATP $\cdot$ Berries $\cdot$ Mitochondria $\cdot$ Ozone

\section{Introduction}

It is well known that a properly designed diet, providing sufficiently large portions of berries, is of crucial importance in maintaining a good physical condition. Highbush blueberry (Vaccinum corymbosum L.) fruit in particular are characterized by a high content of substances with documented health-promoting properties, mainly polyphenol compounds (Wang et al., 2019; Zafra-Stone et al., 2007). Polyphenols have a great ability to scavenge reactive oxygen species (ROS), inhibit the processes of peroxidation of cell components, and chelate metal ions, which are responsible for impaired functioning, the occurrence of mutations, and

Tomasz Piechowiak

tpiechowiak@ur.edu.pl

1 Department of Chemistry and Food Toxicology, Institute of Food Technology and Nutrition, University of Rzeszow, St. Cwiklinskiej 1a, 35-601 Rzeszow, Poland

2 Department of Bioenergetics, Food Analysis and Microbiology, Institute of Food Technology and Nutrition, University of Rzeszow, St. Zelwerowicza 4, 35-601 Rzeszow, Poland consequently, cell death (Diaconeasa et al., 2015; Michalska \& Łysiak, 2015). In addition, blueberry anthocyanins have been found to inhibit the growth of breast cancer, lung cancer, and promyelocytic leukemia cells (in vitro) (Norberto et al., 2013). However, it is advisable to eat the fruit fresh or minimally processed, as heavy processing processes result in a loss of biological properties (Jaramillo-Sánchez et al., 2019). Therefore, in order to extend the shelf life of fruit, it is necessary to use appropriate techniques that will inhibit adverse changes in quality during storage and reduce the level of microorganism.

The ozonation process is a promising method of extending the shelf life of berries (Botondi et al., 2015; Carbone \& Mencarelli, 2015; Horvitz \& Cantalejo, 2014; JaramilloSánchez et al., 2019; Piechowiak et al., 2020a). Ozone, as a substance with strong antimicrobial properties, reduces the level of microorganisms developing on the fruit during storage, oxidizes the released ethylene, and under appropriate process conditions inhibits adverse changes in the level of antioxidants (Ong et al., 2013; Piechowiak et al., 2019a; Sachadyn-Król \& Agriopoulou, 2020). In our previous research, we have proved that ozonation of highbush blueberry fruit with gas at a concentration of $15 \mathrm{ppm}$ for 
30 min, every $12 \mathrm{~h}$ for 28 days of cold storage, inhibits the growth of mesophilic aerobic bacteria and fungi, including Botrytis cinerea mold during storage (Piechowiak et al., 2019a). Moreover, the proposed ozonation conditions activated defense mechanisms against oxidative stress. Ozonated fruit was characterized by a lower level of reactive oxygen species, which was caused by higher activity of antioxidant enzymes and total antioxidant activity (Piechowiak et al., 2020b).

Numerous scientific reports show that the resistance of fruit to adverse changes in quality during storage is related to their mitochondria metabolism (Zhou et al., 2014). Adenosine triphosphate (ATP) produced as a result of aerobic respiration in mitochondria is necessary for cells to maintain their proper activity, the integrity of membranes, and the synthesis of substances with antibacterial and antioxidant properties (Li et al., 2020; Piechowiak et al., 2021). Scientific reports also show that the use of various elicitors, i.e., oxalic acid, benzothiazole, methyl jasmonate, or 1-methylcyclopropene, increases the activity of mitochondria, which corresponds to better fruit quality during storage (Jin et al., 2013, 2014; Li et al., 2020; Shu et al., 2020). In view of the above, it should be assumed that a reduction of adverse changes in the quality of fruit during storage under the influence of ozone may result from both the strong antimicrobial properties of ozone and the influence of ozone on the energy metabolism of the fruit.

The aim of this study was to determine the effect of ozonation on the energy metabolism of mitochondria in highbush blueberry fruit during refrigerated storage. In the course of the study, changes in the energy charge of the activity of enzymes involved in oxidative phosphorylation and the level of selected markers of oxidative stress in the mitochondria of ozonated and control fruit during storage were analyzed. Since antioxidant compounds, mainly polyphenols, are responsible for shaping the quality of blueberry fruit, mainly its biological and sensory properties, and the first stages of their biosynthesis is carried out with the use of ATP, the present study also checked whether there is a relationship between the metabolic activity of mitochondria and the level of polyphenol compounds and antioxidant activity.

\section{Materials and Methods}

\section{Plant material and Storage Procedure}

Blueberry (Vaccinum corymbosm L. cv "Bluecrop") fruits were harvested in July 29, 2020 from a commercial plantation located in Strzyzow, in south-eastern Poland $\left(49^{\circ} 52^{\prime} 15^{\prime \prime} \mathrm{N}, 21^{\circ} 47^{\prime} 28^{\prime \prime} \mathrm{E}\right)$. Blueberries were fully expanded and ripe ( $100 \%$ colored) without obvious signs of infections and physical injuries. After harvest, blueberries were immediately transported to the laboratory within $1 \mathrm{~h}$ and selected for uniform size and absence of defects. Then, the blueberry fruits at the amount of $3 \mathrm{~kg}$ were divided into two equal parts. One part of the fruit was subjected to ozonation, while the other part was a control sample. Blueberries $(1.5 \mathrm{~kg})$ were placed evenly in a plastic container $(\mathrm{L} \times \mathrm{W} \times \mathrm{H}: 0.65 \times 0.35 \times 0.15 \mathrm{~m})$ and ozonated for the total time of experiment with 12-h intervals using gaseous ozone at the concentration of $15 \mathrm{mg} \mathrm{L}^{-1}$ (flow rate $4 \mathrm{~L} / \mathrm{min}$ ) for 30 min. The Korona L5 ozone generator (Piotrków Trybunalski, Poland) and the UV-106 M ozone analyzer (2B Technologies, Boulder, Colorado, USA) were used for ozonation process. Both ozonated and control sample were stored at $4{ }^{\circ} \mathrm{C}$ (65-70\% of relative humidity) for a period of 28 days. Blueberries were collected after $0,7,14,21$, and 28 days of storage and kept at $-67^{\circ} \mathrm{C}$ for further biochemical analysis.

The experiment was performed in triplicate.

\section{Energy Charge Analysis}

The contents of adenosine triphosphate (ATP), adenosine diphosphate (ADP), and adenosine monophosphate (AMP) were analyzed spectrophotometrically using enzymatic methods presented by Tornheim and Schultz (1990a, 1990b). The changes in the absorbance of solutions were measured at $340 \mathrm{~nm}$ using EPOCH microplate reader (Biotek, Winooski, USA), and the results were expressed as g per kg in dry mass of fruit. The obtained results were used to determine the energy charge (EC) of the fruit, in accordance with the following Eq. (1).

$\mathrm{EC}=[\mathrm{ATP}+0.5 \mathrm{ADP}] /[\mathrm{ATP}+\mathrm{ADP}+\mathrm{AMP}]$

\section{Mitochondria Enzyme Activity Analysis}

The extraction of crude mitochondria from blueberries followed the method of Zhou et al. (2014). The succinate dehydrogenase (SDH) in mitochondria was assayed spectrophotometrically using 2,6-dichlorophenolindophenol as an artificial electron acceptor and succinate as the substrate, according to the method presented by Popov et al. (2010). The cytochrome $\mathrm{C}$ oxidase (CCO) activity was determined by measuring the decrease in the absorbance at $550 \mathrm{~nm}$, which was caused by oxidation of ferricytochrome $\mathrm{c}$ by $\mathrm{CCO}$ (Zhou et al., 2014). One unit of the activity of SDH and $\mathrm{CCO}$ was defined as the amount of enzyme causing a 0.01 decrease in absorbance within $1 \mathrm{~min}$ [ $\mathrm{U} \mathrm{mg}^{-1}$ of protein]. The $\mathrm{H}+-$ ATPase activity was determined according to Lin et al. (2017)'s method. One unit of H+-ATPase was defined as the amount of enzyme causing the release of $1 \mu \mathrm{mol}$ of phosphorus from ATP within $1 \mathrm{~h}$ [ $\mathrm{U} \mathrm{mg}^{-1}$ of protein]. 


\section{Determination of ROS Generation by Mitochondria}

The reactive oxygen species generation was analyzed using $2^{\prime}, 7^{\prime}$-dichlorofluorescin diacetate $\left(\mathrm{H}_{2} \mathrm{DCF}-\mathrm{DA}\right)$. The kinetic of the fluorescence increase was measured at $517 / 527 \mathrm{~nm}$ of excitation and emission, respectively, after $2 \mathrm{~h}$ of incubation at $35{ }^{\circ} \mathrm{C}$ using Hitachi F-7000 fluorescence spectrophotometer (Tokyo, Japan). The increase in fluorescence of the solution per minute $\left[\Delta \mathrm{F} \mathrm{min}^{-1}\right]$ was taken as the ROS production unit (Piechowiak \& Balawejder, 2019).

\section{Determination of Mitochondrial Antioxidant Enzyme Activity and Glutathione Level}

The activity of mitochondrial superoxide dismutase (mtSOD) was determined using colorimetric method, which is based on the measurement of the level of inhibition of nitro blue tetrazolium reduction by $\mathrm{mt}-\mathrm{SOD}$ in xanthine/ xanthine oxidase system (Ukeda et al., 1997). One unit of $\mathrm{mt}-\mathrm{SOD}$ was defined as the amount causing a 0.01 increase in absorbance at $550 \mathrm{~nm}$ within $1 \mathrm{~min}$ at $35^{\circ} \mathrm{C}\left[\mathrm{U} \mathrm{mg}^{-1}\right.$ of protein]. The activity of mitochondrial glutathione peroxidase (mt-GPx) was assayed using the protocol described by Piechowiak et al. (2020a). One unit of mt-GPx activity was defined as an amount of enzyme causing the oxidation of $1 \mu \mathrm{mol}$ of glutathione (GSH) within $1 \mathrm{~min}\left[\mathrm{U} \mathrm{mg}^{-1}\right.$ of protein]. The level mitochondrial glutathione (mt-GSH) was determined fluorometrically using o-phthaldialdehyde as a fluorescent probe. The level of mt-GSH was expressed as a $\mathrm{mg}$ of glutathione (mt-GSH) per $1 \mathrm{~g}$ of protein in mitochondrial suspension (Piechowiak et al., 2020a).

\section{Antioxidant Status Analysis}

The antioxidant activity (AA) against 2,2'-azino-bis(3ethylbenzothiazoline-6-sulfonic acid) (ABTS) and 2,2-difenylo1-pikrylohydrazyl (DPPH) radicals was assayed according to the protocol presented by Piechowiak et al. (2019b). Total phenolic content (TPC) was analyzed using Folin-Ciocalteu reagent according to Piechowiak et al. (2019b). The results were expressed as trolox equivalent for AA and gallic acid equivalent for TPC per $1 \mathrm{~kg}$ of dry mass of the fruit. The level of selected polyphenol compounds, i.e., anthocyanins, gallic acid, ellagic acid, rutin, chlorogenic acid, caffeic acid, (-)epicatechin, was determined in crude blueberry extract by means of highperformance liquid chromatography (HPLC) using SYKAM S600 (Ersing, Germany) equipped with photodiode array detector (S 3210) operating at wavelengths between 190 and $900 \mathrm{~nm}$, pump (S 1132), and column thermostat (S 4120). Before injection, samples were filtered through a $0.22-\mu \mathrm{m}$ syringe nylon filter. The tested compounds were separated on Comosil C18 MSII $(4.6 \times 250 \mathrm{~mm}, 1.5 \mu \mathrm{m})$ column. The mobile phase consisted of $1 \%(\mathrm{v} / \mathrm{v})$ formic acid in water (mobile phase $\mathrm{A}$ ) and $1 \%$ $(\mathrm{v} / \mathrm{v})$ formic acid in acetonitrile. A gradient elution at a constant flow rate of $0.7 \mathrm{~mL} \mathrm{~min}^{-1}$ was used according to the following program: $80-20 \%$ A (0-10 $\mathrm{min}), 65-20 \%$ (10-25 $\mathrm{min}$ ), and again $80 \%$ A (25-35 min.). The column temperature was set $30{ }^{\circ} \mathrm{C}$, and injection volume was $5 \mu \mathrm{L}$. The chromatograms were recorded at 280,320, and $520 \mathrm{~nm}$ for different groups of phenolic compounds. The phenolic compounds were identified by comparing the retention times and based on specific PDA spectra with external standards (Tarola et al., 2013). Quantitative determinations were carried out using the calibration curves of individual standards ranging from 0.005 to $0.1 \mathrm{~g} \mathrm{~L}^{-1}$ $\left(R^{2} \geq 0.9998\right)$.

\section{Statistical Analysis}

The significance of differences between ozonated and control fruit during storage was estimated using ANOVA and Student's $t$ test $(\alpha=0.05)$ in STATISTICA 13.0 PL software.

\section{Results}

\section{Changes in ATP, ADP, AMP, and Energy Charge Level}

The presented research shows that the ozonation process causes a clear and positive change in energy charge in fruit during storage. After 7 days of storage an increase in ATP level in ozonated fruit (by 23\%) was observed $(p<0.05$ ), while the level of ATP in the control fruit did not change significantly $(p>0.05)$. In subsequent time period, the level of ATP in both ozone-treated fruit and the control fruit decreased gradually. ADP level and energy charge of ozonated and non-ozonated fruit generally declined with the extension of the storage period. However, the amount of ADP and EC of ozonated sample was higher compared to control $(p<0.05)$ (Fig. 1B, D). The increased consumption of ATP and ADP during storage led to increase in AMP accumulation both in ozonated and control fruit. However, the level of AMP in ozonated fruit was significantly lower than in control during whole period of storage $(p<0.05)$. For example, after 28 days of storage, AMP level in the control fruit increased by $\sim 83 \%$ compared to the initial value, while in ozonated fruit by $25 \%$.

\section{Changes in Oxidative Phosphorylation Enzyme Activity}

After 7 days of storage, a rapid decrease of the activity of $\mathrm{SDH}$ and $\mathrm{H}+-$ ATPase in non-ozonated fruit was observed $(p<0.05)$, while the activity of these enzymes in ozonated fruit did not change significantly $(p>0.05)$. After this time, the activity of SDH and $\mathrm{H}+-$ ATPase gradually decreased with the extension of the storage period. In the case of 


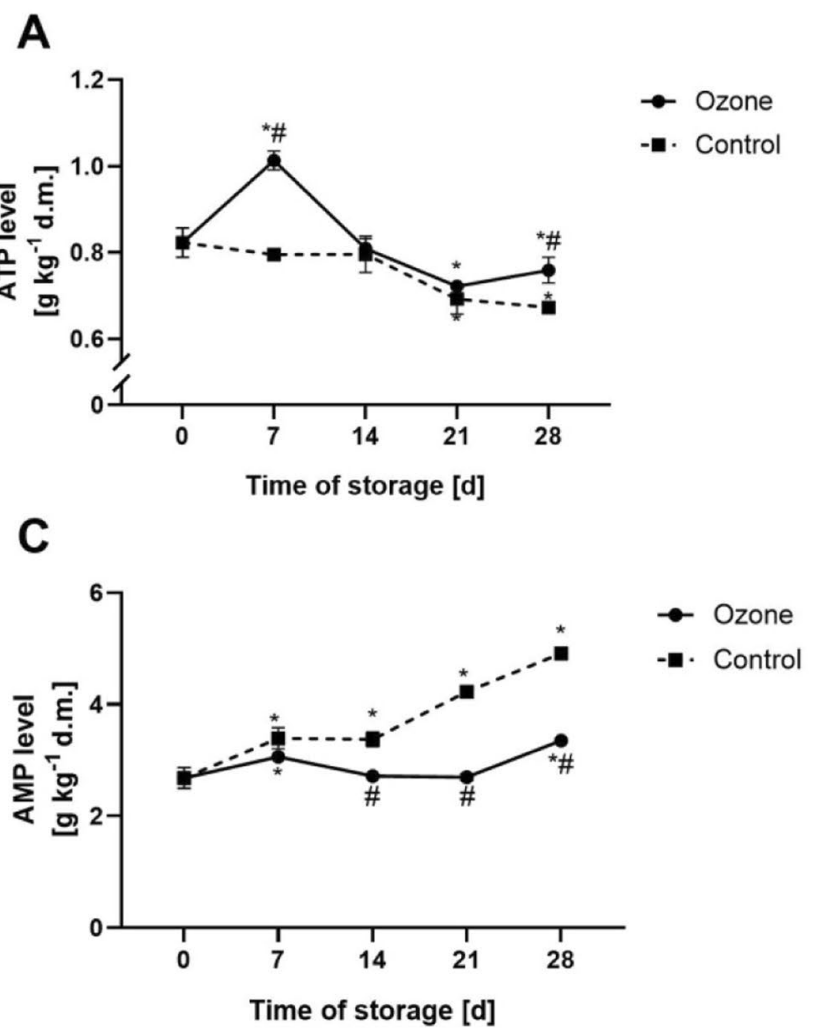

Fig. 1 Changes in the level of ATP (A), ADP (B), AMP (C) and energy charge (D) of blueberry fruit during storage in ozone-enriched atmosphere. Mean values $(n=3)$ with standard deviation (SD) with \# are statistically different from the control at $p<0.05$, in appropri-

cytochrome $\mathrm{C}$ oxidase, it was noted an increase in the activity of these enzyme after 7 days of storage and a gradual decline in subsequent time periods $(p<0.05)$ (Fig. 2). In turn, $\mathrm{CCO}$ activity in non-ozonated fruit demonstrated decreasing tendency along with the extension of the storage period.

\section{Changes in the Level of Oxidative Stress Markers}

Ozone treatment in proposed process conditions increased the production of reactive oxygen species by mitochondria (mt-ROS). As presented in Fig. 3A, the mt-ROS generation in ozonated fruit increased after 7 days of storage (by $~ 58 \%$ ) $(p<0.05)$, while in the control sample, it did not change significantly $(p>0.05)$. After 21 days, the level of mt-ROS increased rapidly in ozonated as well as control fruit.

The activity of superoxide dismutase (mt-SOD) and glutathione peroxidase (mt-GPx) demonstrated a decreasing tendency during the whole period of storage. However, after 7 days of storage, the activity of mt-SOD and mt-GPx in ozonated fruit was higher than in the control sample
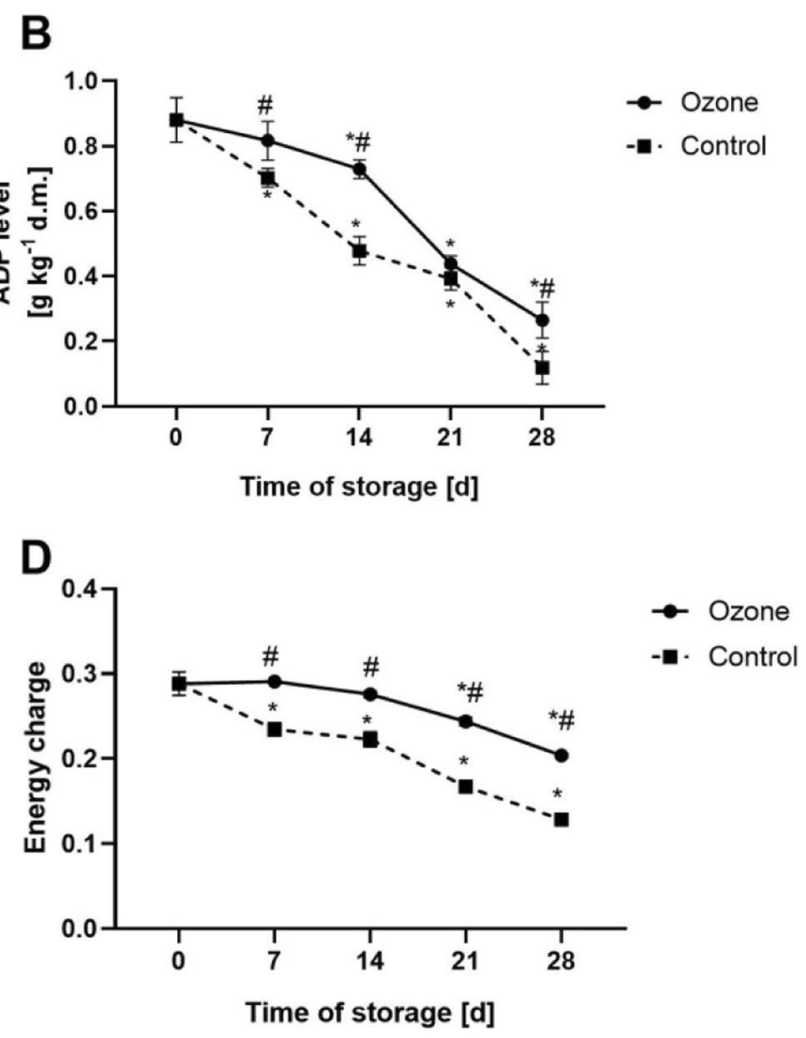

ate day of storage (Student $t$ test). Mean values with * are significant different from the initial value $(0$, day of storage) $(p<0.05$ one-way ANOVA, Tukey test)

$(p<0.05)$. In the subsequent periods, the activity of mt-SOD and mt-GPx in the ozonated fruit was similar to that in the control fruit $(p>0.05)$ (Fig. 3B, C).

Changes in the level of mitochondrial glutathione (mtGSH) are shown in Fig. 3D. After 7 days of storage, the mt-GSH level increased by $35 \%$ in relation to initial value, while in the control sample, it decreased markedly $(p<0.05)$. However, after 14 days, the mt-GSH level in ozonated fruit declined sharply, and it did not change significantly in the subsequent storage periods.

\section{Changes in Antioxidant Status of Ozonated Blueberry Fruit}

The research showed that the ozonation process affects the amount of phenolic compounds as well as the antioxidant activity of the fruit (Fig. 4 and Table 1). Ozonated fruit was characterized by higher ability to neutralize ABTS and DPPH radicals than the control sample through 21 days despite a gradual decrease in antioxidant activity during storage $(p<0.05)$. 


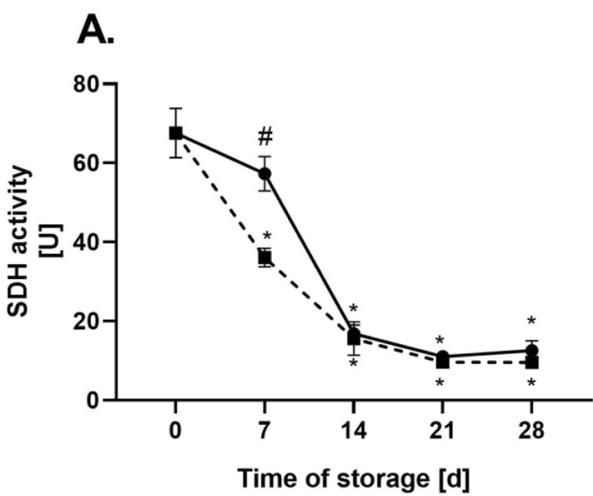

\section{B.}

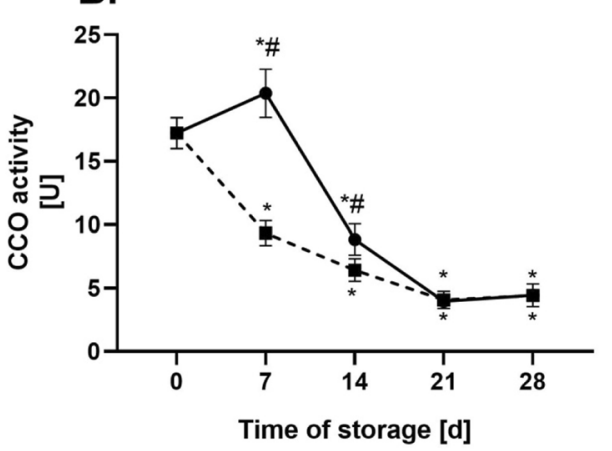

C.

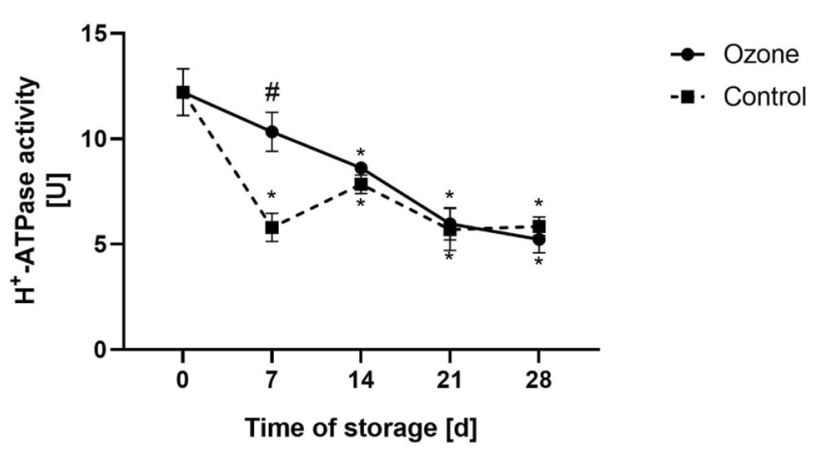

Fig. 2 Changes in the activity of succinate dehydrogenase (A), cytochrome C oxidase (B), H+ATPase (C) in mitochondria in ozonated and control blueberry fruit during storage. Mean values with standard deviation (SD) with \# are statistically different from the control at $p<0.05$, in appropriate day of storage (Student $t$ test). Mean values with * are significant different from the initial value $(p<0.05$ one-way ANOVA, Tukey's test)

HPLC analysis revealed that the ozonation process had different effects on individual polyphenol compounds in the tested fruit (Table 1). It was observed that the content of anthocyanins decreased after 7 days of storage both in the control and in the ozone-treated ones. However, after this time, it was found a gradual increase in anthocyanin accumulation in ozonated fruit and no significant changes in the control fruit. The content of (-)epicatechin and caffeic acid in ozonated fruit increased with the extension of the storage period, while no significant changes were found in the control fruit. The level of chlorogenic acid in ozonated fruit throughout the storage period did not change significantly compared to the initial value. In turn, the content of this compound in control sample gradually decreased. The level of gallic acid decreased sharply after 7 days and then increased gradually both in the ozonated and control sample in the subsequent storage time. However, the content of gallic acid in ozonated fruit was higher than in control sample $(p<0.05)$.

\section{Discussion}

ATP is a key molecule used by plant cells as a source of the energy required to carry out many biochemical reactions necessary for the proper functioning and viability of cells. Also, some enzymatic reactions involved in the initial stages of the biosynthesis of antioxidant compounds require the supply of energy from the breakdown of ATP, e.g., during the phosphorylation of shikimic acid with the participation of shikimic kinase in the shikimic pathway and the conversion of $p$-coumaric acid to $p$-coumaroli-CoA with the participation of 4-coumarate-CoA ligase in the phenylpropanoid pathway as well as during the biosynthesis of glutathione in the participation of $\gamma$-glutamylcysteine synthetase and glutathione synthetase (Hasanuzzaman et al., 2017; Wang et al., 2019). Moreover, the intensity of respiration is related to the production of reactive oxygen species by the mitochondria, which affect antioxidant status of fruit (Blokhina \& Fagerstedt, 2010; Gill \& Tuteja, 2010). Therefore, the presented work provides answers to two fundamental questions. Does storage of highbush blueberries in an ozone-enriched atmosphere affect mitochondrial activity? Is there a relationship between the mitochondrial activity and the improved antioxidant potential of ozonated fruit?

The first stage of the research was to estimate the energy charge of the fruit and the activity of selected enzymes involved in oxidative phosphorylation, i.e., succinate dehydrogenase ( $\mathrm{SDH})$, cytochrome oxidase (CCO), and $\mathrm{H}+$-ATPase. $\mathrm{SDH}$ is an enzyme of respiratory complex II that catalyzes the dehydrogenation of succinate leading to the formation of fumarate (Piechowiak 2021; Zhou et al., 2014). Cytochrome $\mathrm{C}$ oxidase picks up electrons from cytochrome $\mathrm{C}$ and transfers them to an oxygen molecule, reducing it, which leads to the formation of water upon attachment of $\mathrm{H}^{+}$ions in complex IV of electron transport chain (ETC) (Millar et al., 2004). In turn, $\mathrm{H}+\mathrm{ATPase}$ accelerates the breakdown of ATP into ADP, releasing the energy needed to establish a transmembrane electrochemical gradient and transport protons across the membrane during ATP biosynthesis (Zhou et al., 2014). According to Li et al. (2020), the activity of ETC enzymes is closely correlated with the level of ATP and energy charge in a plant cell. Our research has shown that storing fruit 

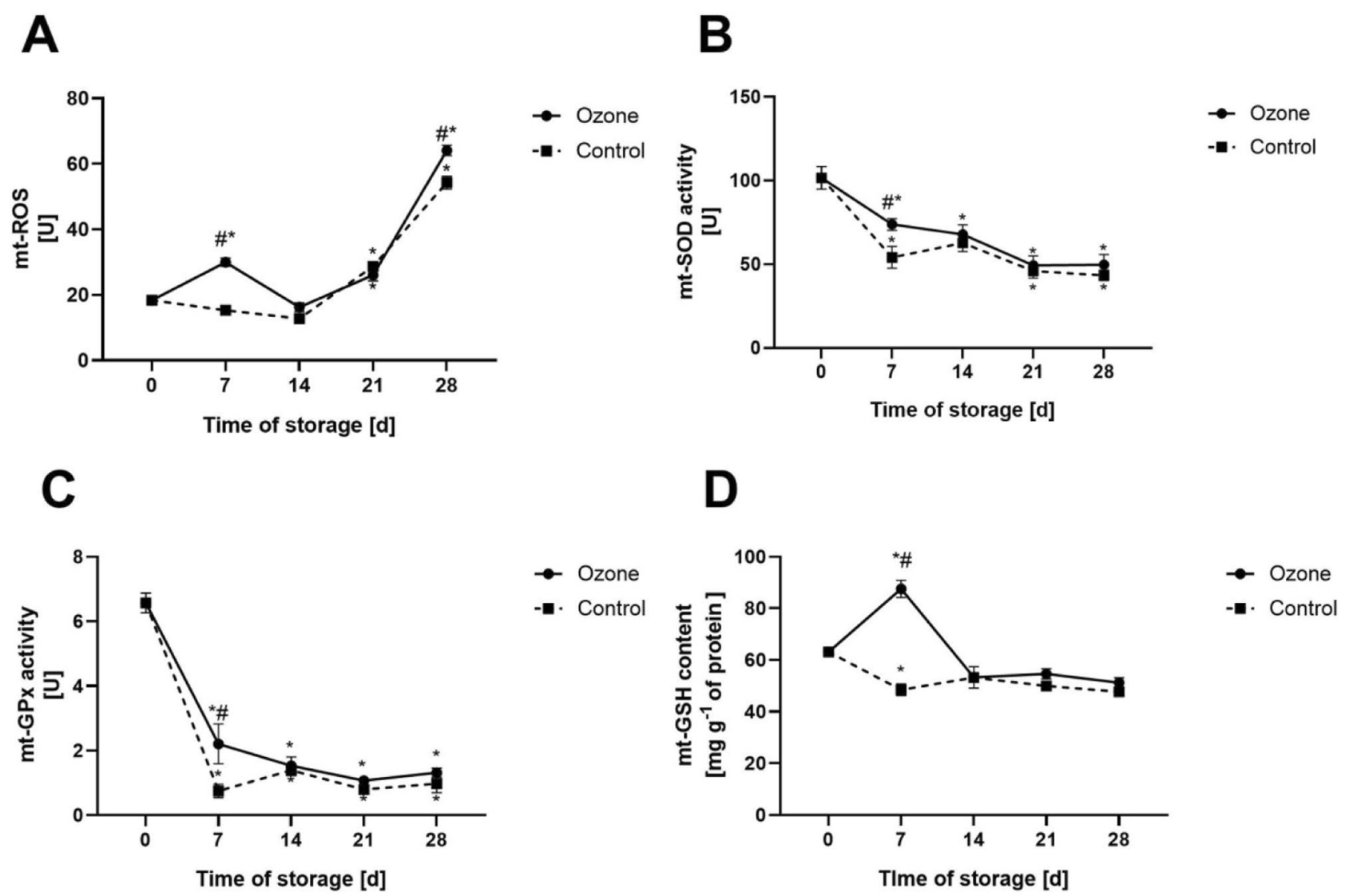

Fig. 3 Changes in oxidative stress markers in mitochondria in ozonated and control blueberry fruit during storage. Mean values with standard deviation (error bars) with \# are statistically different from the control at $p<0.05$, in appropriate day of storage (Student $t$ test). Mean values with * are significant different from the initial value

( $p<0.05$ one-way ANOVA, Tukey's test). A Mitochondrial ROS generation, B mitochondrial superoxide dismutase activity, $\mathbf{C}$ mitochondrial glutathione peroxidase activity, D mitochondrial glutathione level

in an ozone atmosphere improves the activity of the above enzymes, which corresponds to higher level of ATP, ADP, and energy charge of ozonated fruit. Oxygen is the major product of ozone decomposition in the air; therefore, the observed phenomenon could result from the higher activity of oxygen in the storage chamber, which in turn contributed to an increase in the respiration intensity of the fruit. Su et al. (2005) came to a similar conclusion. The authors found that storing Dimocarpus longan in pure oxygen increased the intensity of respiration, resulting in higher ATP level and energy charge of the mitochondria.

Many studies show that that the application of various elicitors after fruit harvesting induces the activity of enzymes involved in the oxidative phosphorylation, intensifying the ATP biosynthesis, and also leading to improved resistance of the plant to abiotic stress (Aghdam et al., 2018). For example, the use of methyl jasmonate improved ATP biosynthesis, thus reducing the degree of damage to loquat fruit caused by Colleotrichum actutaum (Jin et al., 2013). Treatment of

apples with benzothiazole reduced the area of tissue damage exposed to Penicillium expansum, which was closely related to the higher energy status of the fruit (Li et al., 2020). Improved mitochondrial energy metabolism was also noted in peaches exposed to oxalic acid as well as apples treated with trisodium phosphate (Ge et al., 2019; Jin et al., 2014; Shu et al., 2020). However, Lin et al. (2017) came to different conclusions after testing the effect of treatment with hydrogen peroxide on the energy metabolism of loquat fruit. They found that the activities of $\mathrm{H}+$ ATPase, $\mathrm{Ca}^{2+}$ ATPase, and $\mathrm{Mg}^{2+}$ ATPase were reduced in fruit treated with $\mathrm{H}_{2} \mathrm{O}_{2}$, which in consequence contributed to lower ATP content during the entire storage period and, as a result, accelerated the browning of pericarp. It is likely that the hydrogen peroxide applied increased the accumulation of reactive oxygen species in the plant cell, which led to oxidative stress and, as a consequence, oxidative modification of the enzyme proteins involved in the respiratory chain, and increased the activity of enzymes causing enzymatic browning. 

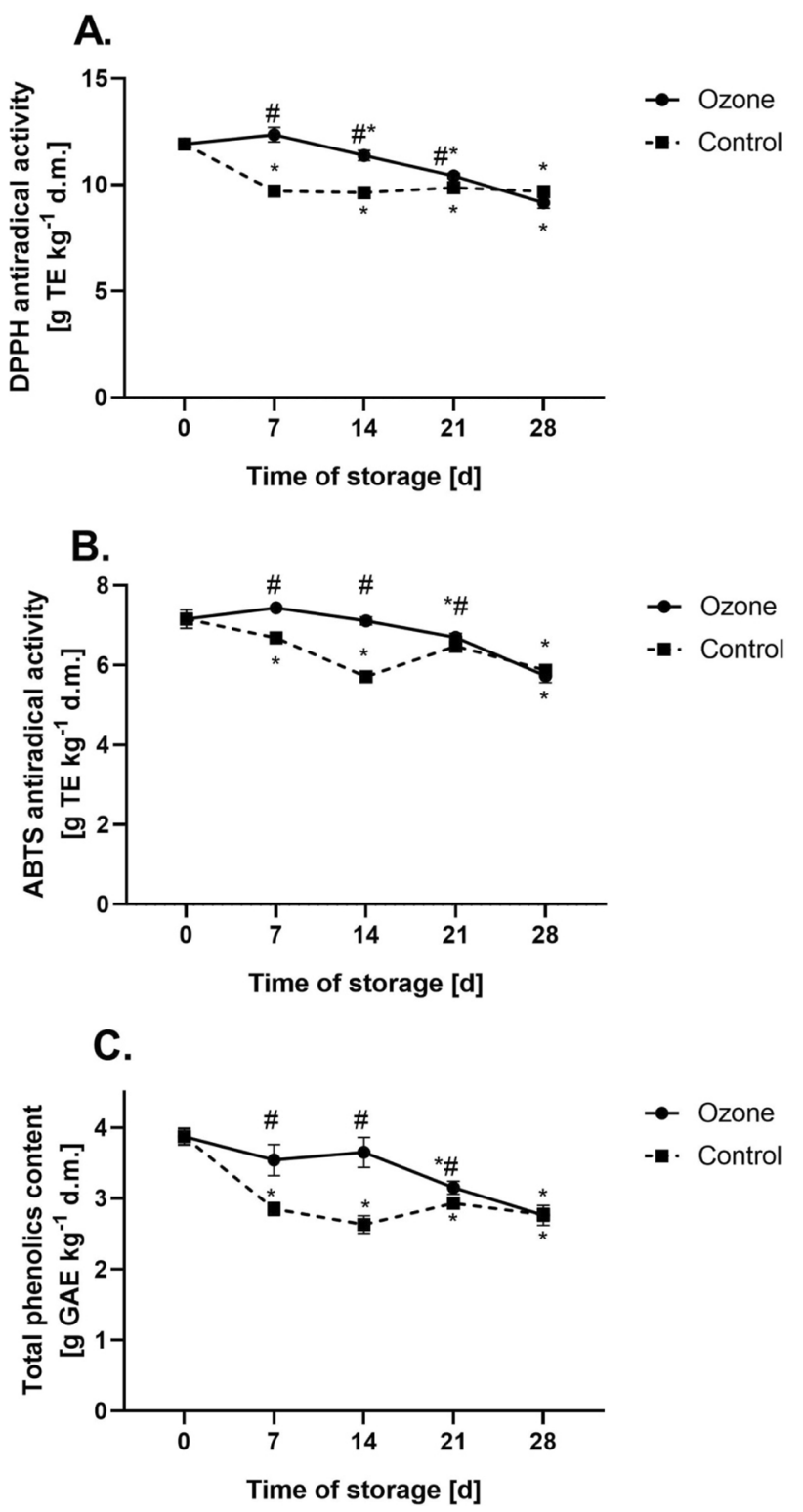

Fig. 4 Changes in antiradical activity (A, B) and total phenolic content $(\mathbf{C})$ in ozonated and control blueberry fruit during storage. Mean values with standard deviation (error bars) with \# are statistically different from the control at $p<0.05$, in appropriate day of storage (Student $t$ test). Mean values with $*$ are significant different from the initial value ( $p<0.05$ one-way ANOVA, Tukey's test)

Reactive oxygen species are a by-product of oxygen respiration. The superoxide anion radical is generated during the electron reduction of oxygen in respiratory complexes I, II, and III (Gill \& Tuteja, 2010). The superoxide radical anion produced can then be reduced to hydrogen peroxide by superoxide dismutase. The hydrogen peroxide produced, in turn, can be neutralized by glutathione peroxidase in the presence of glutathione $(\mathrm{GSH})$ to water (Bailey-Serres \& Mittler, 2006; Mhamdi \& Van Breusegem, 2018). The increase in energy metabolism by ozonation contributed to the increase in ROS generation by mitochondria, and this, in turn, to increase in the activity of mechanisms against oxidative stress (mt-SOD, mt-GPx, glutathione level). In the research presented in Piechowiak et al. (2020b), we observed that the ability to produce superoxide anion radical and hydrogen peroxide in blueberry fruit was lower in ozonated fruit, which was caused by the higher activity of antioxidant enzymes and the level of low-molecular-weight antioxidants. We observed the same effect in raspberry fruit, although the storage and ozonation conditions used were different (Piechowiak \& Balawejder, 2019; Piechowiak et al., 2020a). Therefore, it should be assumed that the effect of ozone in relation to the antioxidant apparatus is multidirectional, because in the case of measuring the level of reactive oxygen species in fruit homogenates, the effect of ozonation was clearly the reverse. Probably, ozone, by increasing the activity of mitochondria, changes the redox state in the cell by increasing the level of the mitochondrial ROS, inducing the expression of genes encoding both antioxidant enzymes and enzymes involved in the biosynthesis of low-molecular-weight antioxidants, which results in the fruit tissue having a higher antioxidant potential and, as a result, being characterized by a lower ROS level. However, to prove this, it is necessary to study other cell organelles responsible for ROS production, as well as to determine the expression of genes encoding selected enzymes of the antioxidant system.

Low-molecular-weight antioxidants apart from the fact that they react with ROS in plant cells are responsible for the shaping quality of the fruit, mainly nutritional value and sensory features (phenolic compounds) (Tomás-Barberán \& Espín, 2001). Many studies have shown that the use of light ozonation conditions causes the activation of the mechanisms involved in the biosynthesis of low-molecular-weight antioxidants and/or inhibits the activity of enzymes catalyzing the decomposition of antioxidants (Piechowiak et al., 2020a; Sachadyn-Król \& Agriopoulou, 2020). This was also confirmed in this research. Ozonation process inhibited the loss of total antioxidants during storage as well as increased the level of some phenolic compounds. Moreover, mitochondria from ozonated fruit had higher glutathione content than from control. Therefore, it should be assumed that ozone, by increasing the energy metabolism of mitochondria, intensifies the biosynthesis of ATP, which provides the necessary energy for basic biochemical changes taking place in fruit, including the biosynthesis of antioxidants. 
Table 1 The level of selected phenolic compounds in blueberry fruit during storage in ozone-enriched atmosphere

\begin{tabular}{|c|c|c|c|c|c|c|c|c|c|}
\hline \multirow{4}{*}{$\begin{array}{l}\text { Com- } \\
\text { pounds }\end{array}$} & \multicolumn{9}{|c|}{ The level of phenolic compounds ( $\mathrm{g} \mathrm{kg}^{-1}$ d.m.) } \\
\hline & \multicolumn{9}{|c|}{ Time of storage (day): } \\
\hline & \multirow[t]{2}{*}{0} & \multicolumn{2}{|l|}{7} & \multicolumn{2}{|l|}{14} & \multicolumn{2}{|l|}{21} & \multicolumn{2}{|l|}{28} \\
\hline & & Ozone & Control & Ozone & Control & Ozone & Control & Ozone & Control \\
\hline $\begin{array}{l}\text { Anthocya- } \\
\text { nins }\end{array}$ & $1.550 \pm 0.08$ & $1.379 \pm 0.07 \#$ & $1.213 \pm 0.06$ & $1.699 \pm 0.08 \#$ & $1.444 \pm 0.07$ & $1.753 \pm 0.09 \#$ & $1.471 \pm 0.07$ & $1.751 \pm 0.09 \#$ & $1.390 \pm 0.07$ \\
\hline Gallic acid & $0.798 \pm 0.04$ & $0.407 \pm 0.02 \#$ & $0.637 \pm 0.03$ & $0.1866 \pm 0.04 \#$ & $0.680 \pm 0.03$ & $0.823 \pm 0.04 \#$ & $0.733 \pm 0.04$ & $0.852 \pm 0.04 \#$ & $0.704 \pm 0.04$ \\
\hline $\begin{array}{l}\text { Chloro- } \\
\text { genic } \\
\text { acid }\end{array}$ & $1.111 \pm 0.04$ & $1.053 \pm 0.04 \#$ & $0.390 \pm 0.02$ & $0.601 \pm 0.02 \#$ & $0.358 \pm 0.01$ & $0.523 \pm 0.02 \#$ & $0.394 \pm 0.02$ & $0.483 \pm 0.02 \#$ & $0.366 \pm 0.01$ \\
\hline $\begin{array}{l}\text { (-)Epicat- } \\
\text { echin }\end{array}$ & $0.066 \pm 0.00$ & $0.065 \pm 0.00 \#$ & $0.042 \pm 0.00$ & $0.084 \pm 0.00 \#$ & $0.054 \pm 0.00$ & $0.106 \pm 0.01 \#$ & $0.070 \pm 0.00$ & $0.101 \pm 0.01 \#$ & $0.049 \pm 0.00$ \\
\hline $\begin{array}{c}\text { Caffeic } \\
\text { acid }\end{array}$ & $0.101 \pm 0.00$ & $0.124 \pm 0.00 \#$ & $0.093 \pm 0.00$ & $0.157 \pm 0.00 \#$ & $0.103 \pm 0.00$ & $0.182 \pm 0.01 \#$ & $0.115 \pm 0.00$ & $0.173 \pm 0.01 \#$ & $0.111 \pm 0.00$ \\
\hline $\begin{array}{l}\text { Quercetin- } \\
\text { 3-O- } \\
\text { rutino- } \\
\text { side }\end{array}$ & $0.041 \pm 0.00$ & $0.039 \pm 0.00$ & $0.037 \pm 0.00$ & $0.036 \pm 0.00$ & $0.038 \pm 0.00$ & $0.035 \pm 0.00$ & $0.039 \pm 0.00$ & $0.031 \pm 0.00 \#$ & $0.028 \pm 0.00$ \\
\hline $\begin{array}{c}\text { Ellagic } \\
\text { acid }\end{array}$ & $0.219 \pm 0.01$ & $0.176 \pm 0.01 \#$ & $0.163 \pm 0.01$ & $0.179 \pm 0.01 \#$ & $0.143 \pm 0.01$ & $0.159 \pm 0.01 \#$ & $0.150 \pm 0.01$ & $0.165 \pm 0.01 \#$ & $0.154 \pm 0.01$ \\
\hline
\end{tabular}

Mean values \pm SD with \# are significant different from non-ozonated fruit (control) at $p<0.05$ (Student $t$ test)

\section{Conclusion}

In conclusion, the results presented here demonstrated the relationship between antioxidative properties and energy metabolism in blueberry fruit during storage in ozoneenriched atmosphere. Research showed that ozonated fruit was characterized by higher activity of enzymes involved in oxidative phosphorylation than non-ozonated sample, which contributed to reduction of the loss of energy charge and ATP in the fruit during storage. Moreover, the increased activity of mitochondria led to the growth of mitochondrial ROS accumulation which, in turn, activated defense mechanisms against oxidative stress in the fruit. These metabolic responses might collectively contribute to increase the antioxidative properties of ozonated fruit and consequently to maintain a good quality of the fruit over a long period of storage. However, based on our results, it is difficult to predict the exact mechanism of the ozone's influence on the energy metabolism of mitochondria; therefore, more research is needed in this field, mainly at the molecular level.

Funding This work was supported by National Science Centre, Poland (OPUS, 2019/35/B/NZ9/01552).

Data Availability The datasets generated during and/or analyzed during the current study are available from the corresponding author on reasonable request.

\section{Declarations}

Ethics Approval Not applicable.
Informed Consent Not applicable.

Conflict of Interest The authors declare no competing interests.

Open Access This article is licensed under a Creative Commons Attribution 4.0 International License, which permits use, sharing, adaptation, distribution and reproduction in any medium or format, as long as you give appropriate credit to the original author(s) and the source, provide a link to the Creative Commons licence, and indicate if changes were made. The images or other third party material in this article are included in the article's Creative Commons licence, unless indicated otherwise in a credit line to the material. If material is not included in the article's Creative Commons licence and your intended use is not permitted by statutory regulation or exceeds the permitted use, you will need to obtain permission directly from the copyright holder. To view a copy of this licence, visit http://creativecommons.org/licenses/by/4.0/.

\section{References}

Aghdam, M. S., Jannatizadeh, A., Luo, Z., \& Paliyath, G. (2018). Ensuring sufficient intracellular ATP supplying and friendly extracellular ATP signaling attenuates stresses, delays senescence and maintains quality in horticultural crops during postharvest life. Trends in Food Science and Technology. https://doi.org/10.1016/j.tifs.2018.04.003

Bailey-Serres, J., \& Mittler, R. (2006). The roles of reactive oxygen species in plant cells. Plant Physiology. https://doi.org/10.1104/pp.104.900191

Blokhina, O., \& Fagerstedt, K. V. (2010). Oxidative metabolism, ROS and NO under oxygen deprivation. Plant Physiology and Biochemistry. https://doi.org/10.1016/j.plaphy.2010.01.007

Botondi, R., De Sanctis, F., Moscatelli, N., Vettraino, A. M., Catelli, C., \& Mencarelli, F. (2015). Ozone fumigation for safety and quality of wine grapes in postharvest dehydration. Food Chemistry. https://doi.org/10.1016/j.foodchem.2015.05.029 
Carbone, K., \& Mencarelli, F. (2015). Influence of short-term postharvest ozone treatments in nitrogen or air atmosphere on the metabolic response of white wine grapes. Food and Bioprocess Technology. https://doi.org/10.1007/s11947-015-1515-y

Diaconeasa, Z., Leopold, L., Rugină, D., Ayvaz, H., \& Socaciu, C. (2015). Antiproliferative and antioxidant properties of anthocyanin rich extracts from blueberry and blackcurrant juice. International Journal of Molecular Sciences. https://doi.org/10.3390/ijms16022352

Ge, Y., Chen, Y., Li, C., Wei, M., Li, X., Li, S., et al. (2019). Effect of trisodium phosphate dipping treatment on the quality and energy metabolism of apples. Food Chemistry. https://doi.org/10.1016/j. foodchem.2018.08.142

Gill, S. S., \& Tuteja, N. (2010). Reactive oxygen species and antioxidant machinery in abiotic stress tolerance in crop plants. Plant Physiology and Biochemistry. https://doi.org/10.1016/j.plaphy.2010.08.016

Hasanuzzaman, M., Nahar, K., Anee, T. I., \& Fujita, M. (2017). Glutathione in plants: Biosynthesis and physiological role in environmental stress tolerance. Physiology and Molecular Biology of Plants. https://doi. org/10.1007/s12298-017-0422-2

Horvitz, S., \& Cantalejo, M. J. (2014). Application of ozone for the postharvest treatment of fruits and vegetables. Critical Reviews in Food Science and Nutrition. https://doi.org/10.1080/10408398.2011.584353

Jaramillo-Sánchez, G., Contigiani, E. V., Castro, M. A., Hodara, K., Alzamora, S. M., Loredo, A. G., \& Nieto, A. B. (2019). Freshness maintenance of blueberries (Vaccinium corymbosum L.) during postharvest using ozone in aqueous phase: microbiological, structure, and mechanical issues. Food and Bioprocess Technology. https://doi.org/10.1007/s11947-019-02358-Z

Jin, P., Zhu, H., Wang, J., Chen, J., Wang, X., \& Zheng, Y. (2013). Effect of methyl jasmonate on energy metabolism in peach fruit during chilling stress. Journal of the Science of Food and Agriculture. https://doi.org/10.1002/jsfa.5973

Jin, P., Zhu, H., Wang, L., Shan, T., \& Zheng, Y. (2014). Oxalic acid alleviates chilling injury in peach fruit by regulating energy metabolism and fatty acid contents. Food Chemistry. https://doi. org/10.1016/j.foodchem.2014.03.103

Li, S., Jiang, H., Wang, Y., Lyu, L., Prusky, D., Ji, Y., et al. (2020). Effect of benzothiadiazole treatment on improving the mitochondrial energy metabolism involved in induced resistance of apple fruit during postharvest storage. Food Chemistry. https://doi.org/ 10.1016/j.foodchem.2019.125288

Lin, Y., Lin, Y., Lin, H., Ritenour, M. A., Shi, J., Zhang, S., Chen, Y., \& Wang, H. (2017). Hydrogen peroxide-induced pericarp browning of harvested longan fruit in association with energy metabolism. Food Chemistry. https://doi.org/10.1016/j.foodchem.2016.12.088

Mhamdi, A., \& Van Breusegem, F. (2018). Reactive oxygen species in plant development. Development (cambridge). https://doi.org/ $10.1242 /$ dev. 164376

Michalska, A., \& Łysiak, G. (2015). Bioactive compounds of blueberries: Post-harvest factors influencing the nutritional value of products. International Journal of Molecular Sciences. https://doi.org/10.3390/ ijms160818642

Millar, A. H., Eubel, H., Jänsch, L., Kruft, V., Heazlewood, J. L., \& Braun, H. P. (2004). Mitochondrial cytochrome c oxidase and succinate dehydrogenase complexes contain plant specific subunits. Plant Molecular Biology. https://doi.org/10.1007/s11103-004-2316-2

Norberto, S., Silva, S., Meireles, M., Faria, A., Pintado, M., \& Calhau, C. (2013). Blueberry anthocyanins in health promotion: A metabolic overview. Journal of Functional Foods. https://doi.org/10. 1016/j.jff.2013.08.015

Ong, M. K., Kazi, F. K., Forney, C. F., \& Ali, A. (2013). Effect of gaseous ozone on papaya anthracnose. Food and Bioprocess Technology. https://doi.org/10.1007/s11947-012-1013-4

Piechowiak, T., Antos, P., Józefczyk, R., Kosowski, P., Skrobacz, K., \& Balawejder, M. (2019a). Impact of ozonation process on the microbiological contamination and antioxidant capacity of highbush blueberry (Vaccinum corymbosum L.) fruit during cold storage. Ozone: Science and Engineering, 41(4). https://doi.org/ 10.1080/01919512.2018.1540922

Piechowiak, T., Antos, P., Kosowski, P., Skrobacz, K., Józefczyk, R., \& Balawejder, M. (2019b). Impact of ozonation process on the microbiological and antioxidant status of raspberries (Rubus ideaeus L.) during storage at room temperature. Agricultural and Food Science, 28(1). https://doi.org/10.23986/afsci.70291

Piechowiak, T., Grzelak-Błaszczyk, K., Sójka, M., Balawejder, M. (2020a). Changes in phenolic compounds profile and glutathione status in raspberry fruit during storage in ozone-enriched atmosphere. Postharvest Biology and Technology, 168. https://doi.org/ 10.1016/j.postharvbio.2020.111277

Piechowiak, T., Skóra, B., \& Balawejder, M. (2020b). Ozone treatment induces changes in antioxidative defense system in blueberry fruit during storage. Food and Bioprocess Technology, 13(7). https:// doi.org/10.1007/s11947-020-02450-9

Piechowiak, T. (2021). Effect of ozone treatment on glutathione (GSH) status in selected berry fruit. Phytochemistry. https://doi.org/10. 1016/j.phytochem.2021.112767

Piechowiak, T., \& Balawejder, M. (2019). Impact of ozonation process on the level of selected oxidative stress markers in raspberries stored at room temperature. Food Chemistry. https://doi.org/10. 1016/j.foodchem.2019.125093

Piechowiak, T., Sowa, P., \& Balawejder, M. (2021). Effect of ozonation process on the energy metabolism in raspberry fruit during storage at room temperature. Food and Bioprocess Technology. https:// doi.org/10.1007/s11947-021-02591-5

Popov, V. N., Eprintsev, A. T., Fedorin, D. N., \& Igamberdiev, A. U. (2010). Succinate dehydrogenase in Arabidopsis thaliana is regulated by light via phytochrome A. FEBS Letters. https://doi.org/10.1016/j. febslet.2009.11.057

Sachadyn-Król, M., \& Agriopoulou, S. (2020). Ozonation as a method of abiotic elicitation improving the health-promoting properties of plant products-a review. Molecules. https://doi.org/10.3390/ molecules 25102416

Shu, C., Zhang, W., Zhao, H., Cao, J., \& Jiang, W. (2020). Chlorogenic acid treatment alleviates the adverse physiological responses of vibration injury in apple fruit through the regulation of energy metabolism. Postharvest Biology and Technology. https://doi.org/ 10.1016/j.postharvbio.2019.110997

Su, X., Jiang, Y., Duan, X., Liu, H., Li, Y., Lin, W., \& Zheng, Y. (2005). Effects of pure oxygen on the rate of skin browning and energy status in longan fruit. Food Technology and Biotechnology.

Tarola, A. M., Van de Velde, F., Salvagni, L., \& Preti, R. (2013). Determination of phenolic compounds in strawberries (Fragaria ananassa Duch) by high performance liquid chromatography with diode array detection. Food Analytical Methods. https://doi.org/10.1007/s12161-012-9431-5

Tomás-Barberán, F. A., \& Espín, J. C. (2001). Phenolic compounds and related enzymes as determinants of quality in fruits and vegetables. Journal of the Science of Food and Agriculture. https://doi.org/10. $1002 /$ jsfa. 885

Tornheim, K., \& Schultz, V. (1990a). Adenosine triphosphate: Enzymatic spectrophotometric determination. The Journal of Nutritional Biochemistry. https://doi.org/10.1016/0955-2863(90)90019-H

Tornheim, K., \& Schultz, V. (1990b). Adenosine diphosphate and adenosine monophosphate: Enzymatic spectrophotometric determination. The Journal of Nutritional Biochemistry. https://doi.org/10. 1016/0955-2863(90)90121-Z

Ukeda, H., Maeda, S., Ishii, T., \& Sawamura, M. (1997). Spectrophotometric assay for superoxide dismutase based on tetrazolium salt 3'- $\{1$-[(phenylamino)-carbonyl]-3,4-tetrazolium $\}$-bis(4-methoxy-6nitro)benzenesulfonic acid hydrate reduction by xanthine-xanthine oxidase. Analytical Biochemistry. https://doi.org/10.1006/abio. 1997.2273 
Wang, J., Xu, J., Gong, X., Yang, M., Zhang, C., \& Li, M. (2019). Biosynthesis, chemistry, and pharmacology of polyphenols from Chinese Salvia species: A review. Molecules. https://doi.org/10. 3390/molecules24010155

Zafra-Stone, S., Yasmin, T., Bagchi, M., Chatterjee, A., Vinson, J. A., \& Bagchi, D. (2007). Berry anthocyanins as novel antioxidants in human health and disease prevention. Molecular Nutrition and Food Research. https://doi.org/10.1002/mnfr.200700002
Zhou, Q., Zhang, C., Cheng, S., Wei, B., Liu, X., \& Ji, S. (2014). Changes in energy metabolism accompanying pitting in blueberries stored at low temperature. Food Chemistry. https://doi.org/ 10.1016/j.foodchem.2014.05.063

Publisher's Note Springer Nature remains neutral with regard to jurisdictional claims in published maps and institutional affiliations. 